\title{
Possibility of Age Determination of Bruises in Living Children Using High Frequency Ultrasonography in Addition to the Naked Eye Estimation
}

\author{
Sahar M. Moustafa ${ }^{1}$
}

${ }^{1}$ Forensic Medicine and Clinical Toxicology Department, Faculty of Medicine, Suez Canal University, Suez, Egypt.

\begin{abstract}
The bruise is a significant injury in the eyes of the law and the need to determine the age of bruises is becoming important in routine clinical settings. Clinicians may be asked to comment on the age of any bruise found during child examination, while the coexistence of old and fresh bruises is a strong evidence for a diagnosis of chronic child abuse. It is accepted by forensic practitioners that visual assessment is far from accuracy and more frequently misleading and till now there is no standardized accepted scheme for bruise age determination. Ultrasonography (US) is a suitable tool for measuring the factors affecting the age of bruises, so the present study aims to investigate the possibility of age the bruises by measuring the depth, thickness and ultrasonography findings of subcutaneous hemorrhage using high-frequency US in a trial to estimate its age with a high degree of accuracy in addition to the naked eye assessment. 48 children of age less than 18 years were enrolled (31 boys and 17 girls) with bruises caused by trauma from accidents. The bruises were examined and photographed by a single observer to age them by naked eye. In addition, the depth, the thickness of subcutaneous hemorrhage and their characters were evaluated by using the high frequency Ultrasonography. The results indicated that naked eye estimation of the bruises was correct in $(66.7 \%)$ of the cases. Ultrasonographic results showed that a fresh thin subcutaneous hemorrhage was observed as a thickening of the fibrous partition (hyperechoic), sometimes with an isoechoic area while fresh thicker bruise was observed as a hyperechoic area scattered around the fibrous partition. The echogenicity of the older bruise is less hyperechoic than the fresh one. The depth of subcutaneous hemorrhage did not generally change with time in contrast with the thickness of the subcutaneous hemorrhage which decreased with time. Ultrasonography estimation was correct in (93.8\%) of the cases so, high frequency Ultrasonography can provide an evaluation of characters, depth and thickness of the bruise and allow a more accurate estimate of its age and may provide a clue that adds more accuracy to the naked eye estimation.
\end{abstract}

Keywords Age bruises, Ultrasonography and Child abuse.

\section{Introduction}

B ruise is defined as a collection of blood, visible to the naked eye as an area of discoloration which has extravasated into surrounding tissues following vascular disruption principally as a result of trauma or as a result of a disease process. Typically bruises are caused by blunt trauma, although they may be accompanying all manner of injuries (Vanezis, 2001).

The bruise is a significant injury in the eyes of the law (Langlois, 2007) that it can provide a wealth of information to assist the pathologist to draw reasonable conclusions regarding its causation and assist reconstruction of events leading to death (Vanezis, 2001).

The need to determine the age of bruises becomes more and more important in routine clinical settings especially in light of the more stringent legal obligations of physicians and other health care professionals (Bryson, 1994). The skin is the most common organ involved in accidental or nonaccidental injuries in children, and up to $90 \%$ of victims of physical abuse present with skin features (Kos and Shwayder 2006).

There are discrepancies between physical findings and the history given of child abuse and 
clinicians may be asked to comment on the age of any bruise found during examination of the child (Langlois, 2007) where the coexistence of both old and fresh bruises is a strong evidence for a diagnosis of chronic abuse (Hobbs et al., 1999).

The means by which the bruise was inflicted and its age should be determined by macroscopic observation of its form, color and size in an attempt to diagnose physical child abuse. An estimation of the age of a bruise may be attempted by direct visual examination or by the inspection of photographs taken of the injured area (Hughes et al., 2004) but these methods are subjective in nature and may not be reliable (Munang et al., 2002). However, it is accepted by forensic practitioners that visual assessment, is far from accurate and more frequently misleading. As there is no standardized or single accepted scheme by which visual dating is carried, a considerable variation between different observers is resulted (Langlois, 2007).

Forensic investigators would benefit from a noninvasive, objective, scientifically validated method for determining the age of bruises. They have suggested that either colorimetry or reflectance

spectrophotometry might provide a solution (Yajima et al., 2003 \& Randeberg et al., 2004).

Spectrophotometry was used to estimate the age of a bruise by only evaluating the color of a bruise. The color of a bruise depends not only on its age, but also on its site and depth, as well as the complexion of the skin (Mimasaka, 2006). The depth from the skin surface to the subcutaneous hemorrhage and the thickness of subcutaneous hemorrhage has a great influence on the color changes of a bruise (Mimasaka, 2006\&. Mimasaka et al., 2010).

However, it is difficult to measure the depth and thickness of a subcutaneous hemorrhage in the living, Ultrasonography is suitable for measuring these factors, but Ultrasonographic imaging of subcutaneous hemorrhages has not been established yet (Mimasaka et al., 2012).

Most published work in this field is based on personal practice or "expert" opinion so, the present study aims to investigate whether it is possible to study the bruise by measuring its depth, thickness and Ultrasonographic findings by using high frequency Ultrasonography in a trial to estimate the age of the bruise with a high degree of accuracy in a trial to estimate the age of the bruise with a high degree of accuracy in addition to the naked eye assessment.

\section{Subjects and Methods}

According to standard ethics drawn by the King Saud University Ethical Committee for human researches and after obtaining the committee approval, children with bruises were recruited from the waiting room of the Accident and Emergency Department at the King khaled Hospital in Riyadh City, Saudi Arabia. Forty eight children of age less than 18 years old with bruises from trauma were enrolled.

Children with suspected non-accidental injuries, multiple injuries, history of bleeding disorders and dark-skinned were excluded from the study as the bruise appears dull in dark skin.

The sites of the bruises were standardized (lower or upper limbs) as the bruise may be less visible in thick or fatty areas (Thavarajah et al., 2012).

The written consent was obtained for recruitment after the purpose and procedure of the study had been explained to the parents. The time of bruises inflicted and the type of accident were obtained from the parents and the actual age of the bruise was recorded after history taking and immediate clinical examination. The bruises were photographed using a Pentax MZ-50 single lens reflex camera with a built-in flash and an $80-\mathrm{mm}$ Macro lens and a reproducible color scale included in the field. The photographs were reviewed by a single observer (fellow or resident) blind to the true age of the bruise. According to Stephenson and Bialas, (1996) the 'blind' observer was asked to review the bruise photograph and record the colors present (described as one or more of red, blue, purple, grey, green, brown and yellow) and to estimate the age of the bruise as fresh (48 hours or less), intermediate (between 48 hours and seven days), or old (more than seven days) (Table 1).

After taking the approval of the head of the Radiological Department, the bruise was assessed by evaluating the depth from the skin surface to the subcutaneous hemorrhage and the thickness of subcutaneous hemorrhage in addition to their Ultrasonic characters using the high frequency Ultrasonography (SonoSite180PLUS, SonoSite, Inc., USA), which is a small portable machine with a linear probe (L38/20, SonoSite, Inc., USA) which provided superior observation of superficial tissue was connected to the Ultrasonography and the probe had a $20 \mathrm{MHz}$ transducer. In the other hand the healthy side considered as a control.

Collected data were subjected to statistical analysis using SPSS 16 program (SPSS Inc., Chicago, IL). The variability was expressed as the mean \pm standard error (SE) of the mean and percentage.

\section{Results}

\section{Descriptive data of the bruises cases from history:}

Table (2) showed that a total of 48 bruises were found in 31 boys and 17 girls, with ages ranging from 3 to 11 years (the mean age of these children was $(5.5 \pm 2.7)$. 27 patients $(56.25 \%)$ were pedestrians or involved in road traffic accidents and the remaining $21(43.75 \%)$ sustained falls from a height. Of the 48 bruises, 28 $(58.3 \%)$ involved the upper limb and $20(41.7 \%)$ in the lower limb and no child considered as multiple injured patient. Only 6 children $(12.5 \%)$ remained in the inpatient department for follow up and were therefore photographed days later.

\section{Naked eye estimation of the age of bruises from clinical examination:}

Table (3) showed that the actual ages of the bruises vary from 1 hour to 3 days. In 22 patients (45.8\%) the 
age was 12 hours or less, in 15 patients $(31.3 \%)$ the age was more than 12 hours to one day, in 6 patients $(12.5 \%)$ the age was from one day to two days while the age of two days to three days found in 5 patients $(10.4 \%)$ and nobody in the range of more than 3 days old. The Purple and blue colors were ascribed to the bruises at the time of patient arrival to the hospital in all the patients according to the history and clinical examination. Purple coloration was ascribed only to bruises with age of two days old or less, and was described in 43 out of the 48 bruises $(89.6 \%)$ which considered as fresh. Blue coloration was described in 5 remaining cases $(10.4 \%)$ with age of more than two days but less than three days old which considered as intermediate. Green and yellow coloration were not seen in the bruises less than one week old.

Table (4) showed that according to naked eye estimation 29 cases out of 43 true fresh bruises estimated as fresh and 3 cases out of 5 true intermediate bruises estimated as intermediate while no photograph of fresh or intermediate bruises was estimated as being old., so the naked eye estimation was correct and correlated with the history and clinical examination in 32 out of the 48 cases $(66.7 \%)$ and incorrect in 16 cases $(33.4 \%$ ) according to the single observer revision to the photographs.

\section{Chronologic changes of bruises using high frequency Ultrasonography:}

Table (5) revealed that there is a statistically significant difference between the mean of thickness of the fresh and intermediate bruises as the fresh thin subcutaneous hemorrhage was observed as a thickening of the fibrous partition (hyperechoic), sometimes with an isoechoic area as shown in (Fig.1 \& 2) and was different from the slight linear hyperechoic pattern of the fibrous partition in the control and the intermediate bruise in (Fig. 4) so, the thickness of the hemorrhage decrease with time. Thicker fresh bruises were observed as a hyperechoic area scattered around the fibrous partition (Fig.3). There is a statistically nonsignificance difference between the mean of the depth of fresh and intermediate bruises, so the depth of the hemorrhage did not generally change with time while the echogenicity of the intermediate bruise is less hyperechoic than the fresh one as shown in (Fig.5).

Table (6) showed that according to high frequency Ultrasonography estimation 40 cases out of 43 true fresh bruises estimated as fresh and 5 cases out of 5 true intermediate bruises estimated as intermediate so, the Ultrasonography estimation was correct and correlated with the history in 45 cases out of the 48 cases $(93.8 \%)$ and incorrect in 3 cases $(6.2 \%)$ only.

Table 1: Schemes of the bruises age according to Forensic literatures citing the color changes with time.

\begin{tabular}{|l|l|l|l|l|l|}
\hline Age of the bruise & $\begin{array}{c}\text { Rentoule and Smith } \\
(\mathbf{1 9 7 3})\end{array}$ & \multicolumn{1}{|c|}{$\begin{array}{c}\text { Adelson } \\
(\mathbf{1 9 7 4})\end{array}$} & $\begin{array}{c}\text { Camps } \\
\mathbf{( 1 9 7 6 )}\end{array}$ & $\begin{array}{c}\text { Spitz and Fisher } \\
\mathbf{( 1 9 8 0 )}\end{array}$ & $\begin{array}{c}\text { Polson and Gee } \\
(\mathbf{1 9 8 4})\end{array}$ \\
\hline Initial & Violet Red & Red/blue & Red & Blue/ red & Black \\
\hline $1-3$ days & Dark blue & Blue/brown & Purple, black & Purple dark & Purple/black \\
\hline 1 week & Green & Yellow/green & Green & Green/ yellow & Green \\
\hline $8-10$ day & Yellow & yellow & & \\
\hline 2 weeks & Normal & Normal & Normal & Normal \\
\hline
\end{tabular}

Table 2: Descriptive data of the bruises according to the history.

\begin{tabular}{|l|l|l|}
\hline \multicolumn{1}{|c|}{ Variable } & \multicolumn{1}{c|}{ No. $(\%)$} & \multicolumn{1}{c|}{ No. $(\%)$} \\
\hline Sex & Male 31 (64.6\%) & Female 17 (35.4\%) \\
\hline Cause of injury & Traffic accidents 27 (56.25\%) & Fall from a height 21 (43.75\%) \\
\hline Site of the bruise & Upper limb 28 $(58.3 \%)$ & Lower limb 20 $(41.7 \%)$ \\
\hline Admission in hospital & Admission 6 (12.5\%) & No admission 42 $(87.5 \%)$ \\
\hline
\end{tabular}

Table 3: Naked eye estimation of the age of bruises according to history and clinical examination.

\begin{tabular}{|l|l|l|l|}
\hline \multicolumn{1}{|c|}{ The bruises age } & Color of bruises & No. of cases & \% of cases \\
\hline 12 hours or less & Purple & 22 & 45.8 \\
\hline More than 12 hours to one day & Purple & 15 & 31.3 \\
\hline one day to two days & Purple & 6 & 12.5 \\
\hline Two days to three days & Blue & 5 & 10.4 \\
\hline
\end{tabular}

Table 4: Naked eye estimation of the age of bruises from photographs.

\begin{tabular}{|l|c|c|c|c|}
\hline \multicolumn{1}{|c|}{ Bruises } & $\begin{array}{c}\text { Estimated fresh } \\
\text { No. of cases }\end{array}$ & $\begin{array}{c}\text { Estimated intermediate } \\
\text { No. of cases }\end{array}$ & $\begin{array}{c}\text { Estimated old } \\
\text { No. of cases }\end{array}$ & Total \\
\hline True fresh & 29 & 14 & - & 43 \\
\hline True intermediate & - & 3 & 2 & 5 \\
\hline True old & - & - & - & - \\
\hline Total & 29 & 17 & 2 & 48 \\
\hline
\end{tabular}

Fresh $\leq 48$ hours, Intermediate $>48$ hours and $\leq 7$ days, Old $>7$ days 
Table 5: Chronologic changes of the bruises using high frequency ultrasonography.

\begin{tabular}{|l|l|l|l|}
\hline The bruise (No.) & Depth Mean \pm SE $(\mathbf{c m})$ & Thickness Mean \pm SE $(\mathbf{c m})$ & Ultra sonographic findings \\
\hline Thin fresh (34) & $0.27 \pm 0.05$ & $0.39 \pm 0.08 \mathrm{a}$ & $1^{*} \& 3^{*}$ \\
\hline Thick fresh (9) & $0.29 \pm 0.11$ & $0.74 \pm 0.12 \mathrm{a}$ & $4^{*}$ \\
\hline Intermediate (5) & $0.23 \pm 0.09$ & $0.29 \pm 0.04 \mathrm{a}$ & $3^{*}$ \\
\hline
\end{tabular}

Fresh $\leq 48$ hours, Intermediate $>48$ hours and $\leq 7$ days, $1^{*}$ : Thickening of the fibrous partition (hyperechoic).

$2 *$ : An isoechoic area., $3 *$ : Thickening of the fibrous partition (hyperechoic) with an isoechoic area.

$4^{*}$ : An isoechoic or hyperechoic area scattered around the fibrous partition, ${ }^{a}$ Significant at $P \leq 0.05$

Table 6: Estimation of the age of bruises using high frequency Ultrasonography

\begin{tabular}{|l|c|c|c|c|}
\hline The bruise ( No) & $\begin{array}{l}\text { Estimated fresh } \\
\text { No. of cases }\end{array}$ & $\begin{array}{l}\text { Estimated intermediate } \\
\text { No. of cases }\end{array}$ & $\begin{array}{l}\text { Estimated old } \\
\text { No. of cases }\end{array}$ & Total \\
\hline Fresh (43) & 40 & 3 & - & 43 \\
\hline Intermediate (5) & 5 & - & - & 5 \\
\hline Total & 45 & 3 & - & 48 \\
\hline
\end{tabular}

Fresh $\leq 48$ hours, Intermediate $>48$ hours and $\leq 7$ days

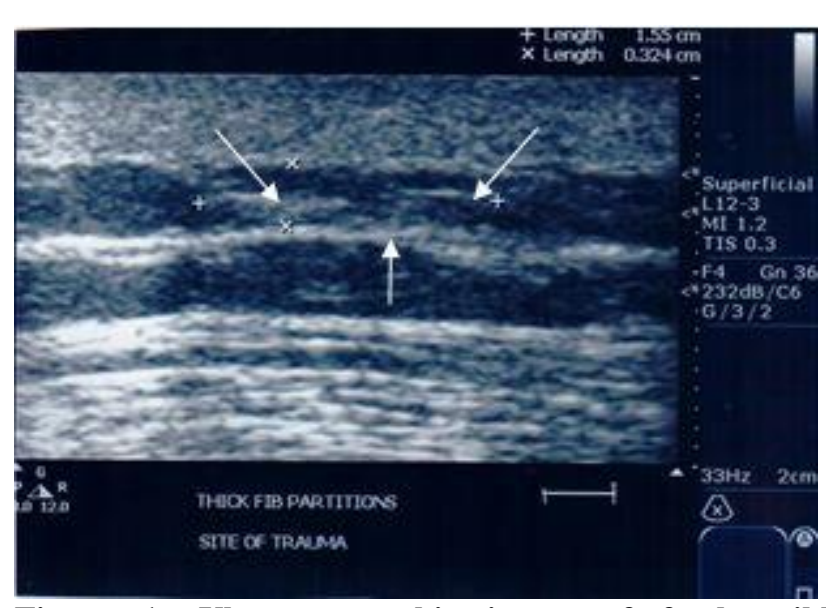

Figure 1: Ultrasonographic image of fresh mild subcutaneous hemorrhage on the upper limb in 10 years old child (white arrows: thickening of the fibrous partition (hyperechoic) with an isoechoic area

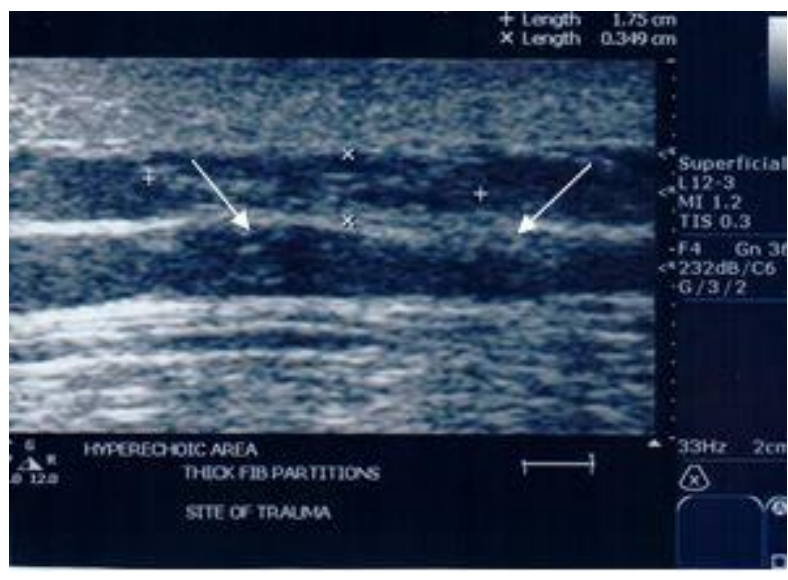

Figure 2: Ultrasonographic image of fresh mild subcutaneous hemorrhage on the lower limb in 3 years old child (white arrows: thickening of the fibrous partition (hyperechoic).

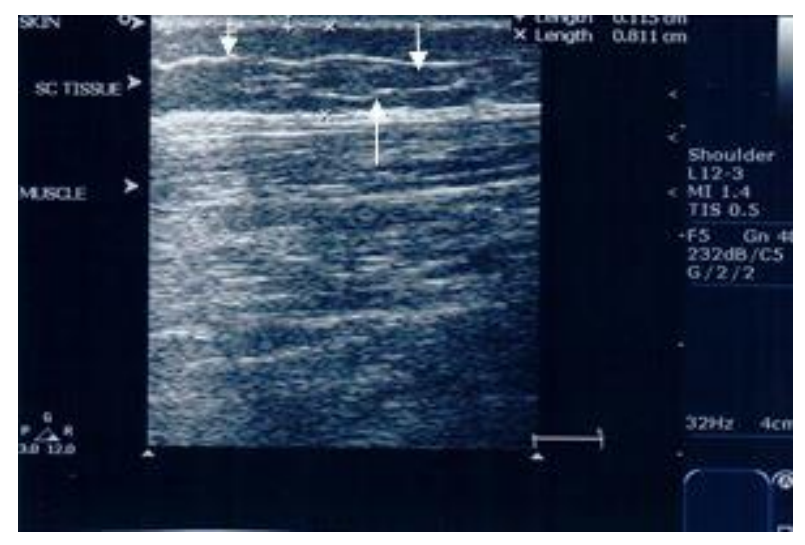

Figure 3: Ultrasonographic image of moderate thick subcutaneous hemorrhage on the lower limb in 4 years old child (white arrows: hyperechoic area scattered around the fibrous partition

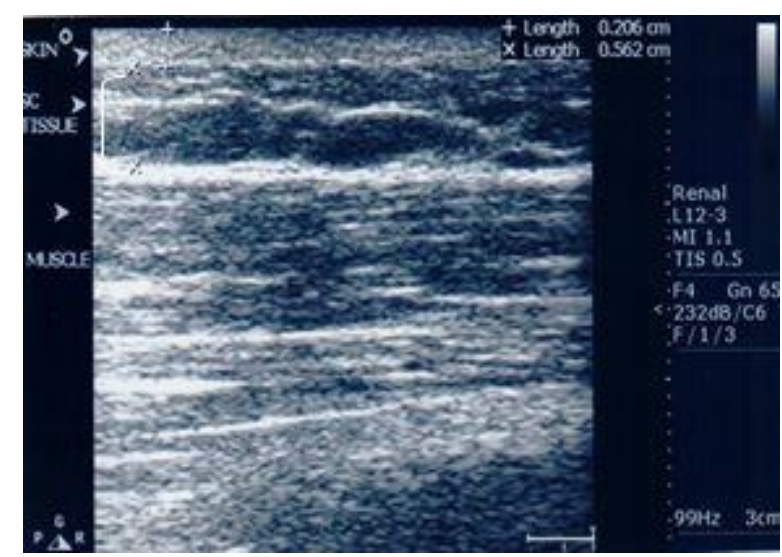

Figure 4: Ultrasonographic image of intermediate subcutaneous hemorrhage on the lower limb in 7 years old child (white [: the thickness of a subcutaneous hemorrhage decreased with time 


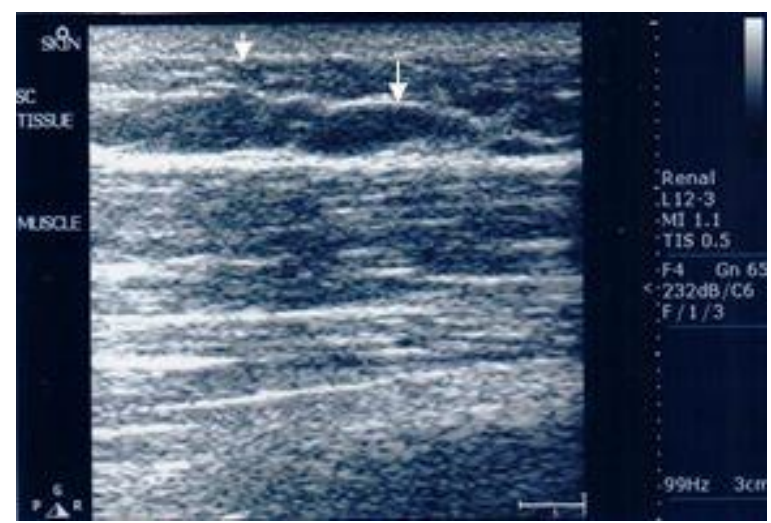

Figure 5: Ultrasonographic image of intermediate 3days old subcutaneous hemorrhage on the upper limb in 4 years old child (white arrows: less hyperechoic thickening of the fibrous partition

\section{Discussion}

Bruises are a much neglected branch of injuries" these words were delivered by the late Sir Bernard Spilsbury (1939) in an address to the Medico-Legal Society and little has changed since then. Forensic pathologists are aware of the importance of recording details of injuries on a victim's body and as an "expert witness" the forensic pathologist is often asked to age a bruise which has been faithfully recorded (Langlois, 2007).

The aging of injuries is an important aspect of forensic medicine, which can have significant medicolegal consequences (Trujillo et al., 1996).

The sequence and timing of color changes associated with the appearance and disappearance of bruises, as well as the factors which govern this process, have long been a source of controversy (Vanezis, 2001).

Published reports on the aging of bruises are confusing. Forensic textbooks which cite the color changes which a bruise undergoes with time do not appear to be based on research in children and there is neither general consensus on the duration of each stage of color, nor even any agreement on the exact sequence of color changes (Stephenson and Bialas 1996).

In the present study, the results revealed that, according to the blind observer opinion, Purple and blue coloration were ascribed to photographs taken at the time of patient arrival to the hospital. Purple coloration was ascribed only to bruises with age of two days old or less, and was described in $89.6 \%$ of cases which considered as fresh. Blue coloration was described in $10.4 \%$ of cases with age of more than two days but less than three days old which considered as intermediate. Green and yellow colors were not seen in bruises less than one week old.

These results indicated that the estimate age of bruises was correct in $66.7 \%$ of the cases. These results are in accordance with Stephenson and Bialas (1996) results which revealed that aging of injuries from photographs is imprecise, even in a controlled research setting. Even using the crude categories of 'fresh', 'intermediate', and 'old', aging of bruises from photographs appears to be unreliable, except that bruise over 48 hours old is unlikely to be estimated as fresh from photographs. In a study for assessment of physician accuracy of dating of the bruises, the results estimated that physician estimation are highly inaccurate within 24 hours of the actual age of the injury and there is a large individual variability and poor reliability (Bariciak et al., 2003).

In another study on the bruises in an attempt to develop an objective technique for aging of bruises, the results documented that visual assessment of bruises is unreliable and the accuracy of aging was not improved by the degree of forensic experience also the results within subjects suggested that there may be individual variation in hemoglobin metabolism (Grossman et al., 2011).

Visual aging of bruises remains an inexact science, despite recent composite charts that suggest otherwise, even though it has been stated that it is not possible to age bruises accurately based on color (Schwartz and Ricci., 1996). Macroscopic and spectrophotometric examinations of bruises have limitations in evaluating subcutaneous hemorrhages because they depend solely on the external changes in the color of the bruise (Mimasaka et al., 2012).

The characteristics of a bruise are influenced by its site, an individual's bleeding tendency and skin color, the force of injury, depth, and extent of subcutaneous extravasation. While many textbooks are definitive in their statements about the appearance of "fresh", "old", or "recent" bruises, the evidence behind this classification may not be robust (Maguire et al., 2005). So, while child abuse is one of the most difficult crimes to detect and prosecute in large part because there often are no witnesses except the victim (Schwartz and Ricci., 1996) the introduction of a reliable, non-invasive and simple methods to detect the age of subcutaneous hematomas after external visual examination can represent a valid adjunct to its clinical aging. Ultrasonography technique has been applied to measurement of soft tissue thickness and depth in the forensic field (De Greef et al., 2005). 
The present results found that there is a statistically significant difference between the mean of thickness of the fresh and intermediate bruises as the thin fresh bruise was observed as a thickening of the fibrous partition (hyperechoic), sometimes with an isoechoic area and thicker fresh bruises were observed as a hyperechoic area scattered around the fibrous partition in contrast with the control subcutaneous layer which appears hypoechoic fat area and hyperechoic connective tissue septa on Ultrasound as stated by Valle and Zamoirini., (2007).

These results are in accordance with the results of Mimasaka et al, (2012) who reported that fresh hematomas appear as an ill-defined hyperechoic area because mild hemorrhage spreads only around the fibrous partition (hyperechoic), it may appear as a thickening of the fibrous partition in the Ultrasonographic image.

A moderate hemorrhage spreads around the fibrous partition and its echo enlarges and appears as an isoechoic or hyperechoic area scattered around the fibrous partition. The present results detected that the depth of subcutaneous hemorrhage did not generally change with time and in contrast the results are able to confirm that the thickness of a subcutaneous hemorrhage decreased with time. These are in accordance with a study which concluded that the extent of a bruise may increase considerably after the injury which caused it, because of continued extravasation of blood and tracking between tissue planes (Stephenson and Bialas., 1996).

Although the color of blood is red, due to the hemoglobin molecule, the appearance of extravasated blood within the skin varies according to its oxygenation and the depth of its location below the skin surface (Bohnert et al., 2000).

A recent study evaluating the age bruises by spectrophotometry concluded that determination of the depth from the skin surface to the subcutaneous hemorrhage and the thickness of a subcutaneous hemorrhage precisely may provide a clue that adds to the accuracy of the spectrophotometric evaluation of a bruise (Mimasaka et al., 2012).

The present results revealed that the echogenicity of the of old bruise (3days old) is less hyperechoic than the fresh one which agree with Mimasaka et al, (2012) results that indicated that in old bruises of more than two days old, the isoechoic area of subcutaneous hemorrhage was clear in the bruise. The present results revealed that Ultrasonography estimation was correct and correlated with the history in $(93.8 \%)$ which add a clue to accurate estimation of age of the bruise. Moreover, the present results are in accordance with those of Commrota et al, (1998) who revealed that high frequency Ultrasound can provide a reliable morphologic representation of skin and subcutaneous lesions and its application to dermatology is very challenging.

\section{Conclusion}

The present study indicates that Ultrasonography evaluation of the bruise can add a clue to the naked eye evaluation that might help for an accurate estimation of age of bruises.

\section{Acknowledgments}

We express our sincere thanks to the staff members of Department of Radiology in King Khaled Hospital in Riyadh City in Saudi Arabia Kingdom for providing the facilities and technical support for this stud.

\section{References}

Bariciak ED, Plint AC, Gaboury I et al., (2003): Dating of bruises in children: an assessment of physician accuracy. Paediatrics. 112(4): 8047.

Bohnert M, Baumgartner R and Pollak S (2000): Spectrophotometric evaluation of the color of intra- and subcutaneous bruises. Int. J Legal Med.113: 343-8.

Bryson D (1994): A guide to medico-legal photography for personal injury claims. J. Audiovis. Media Med. 17: 5-11.

Commarota T, Pinto F, Magliaro A et al., (1998): Current uses of diagnostic high-frequency US in dermatology. Eur. J Radiol. 27 Suppl. 2: S215-23.

De Greef S, Claes P, Mollemans W et al., (2005): Semi-automated ultrasound facial soft tissue depth registration: method and validation. $\mathbf{J}$ Forensic Sci. 50:128.

Grossman SE, Johnston A, Vanezis P et al., (2011): Can we assess the age bruises? An attempt to develop an objective technique. Med. Sci. Law. 51(3): 170-6.

Hobbs CJ, Hanks HGI and Wynne JM (1999): Child Abuse and Neglect: A Clinician's Handbook. London, New York: Churchill Livingstone. pp. 63-10.

Hughes VK, Ellis P and Langlois NE (2004): The perception of yellow in bruises.J Clin. Forensic Med.11:257-9.

Kos L and Shwayder T (2006): Cutaneous manifestations of child abuse. Pediat. Dermatol. 23: 311-20.

Langlois NE (2007): The science behind the quest to determine the age of bruises-a review of the English language literature. Forensic Sci. Med. Pathol. 3 (4):241-51.

Maguire S, Mann MK, Sibert J et al., (2005): Can you age bruises accurately in children? A systematic. Review. Arch. Dis. Child. 90:187189.

Mimasaka S (2006): Age of bruises in children; useful as diagnostic evidence of child abuse. In: Sotony P, editor. Proceedings of the 20th Congress of the International Academy of Legal Medicine. Budapest: Medimond. Srl. p. 53-5.

Mimasaka S, Ohtani M, Kuroda N et al., (2010): Spectrophotometric evaluation of the age of bruises in children: measuring changes in bruise color as an indicator of child 
physical abuse. Tohoku J Exp. Med. 220: 171-5.

Mimasaka S, Oshima T and Ohtani M (2012): Characterization of bruises using Ultrasonography for potential application in diagnosis of child abuse, Legal Medicine. 14: $6-10$.

Munang LA, Leonrd PA and Mok JY (2002): Lack of agreement on color description between clinicians examining childhood bruising. J Clin. Forensic Med. 9:171-4.

Randeberg LL, Winnem A, Blindheim S et al., (2004): Optical classification of bruises. Proc. SPIE. 5312: 54-64.

Schwartz AJ and Ricci L R (1996): How accurately can bruises be aged in abused children? Literature review and synthesis. Pediatrics. 97 (2): 254257.

Spilsbury B (1939): The medico-legal significance of bruises. Med. Leg. Grim. Rev., 1939; 7: 215227.

Spitz WU and Fisher RS (1980): Medico-legal investigation of death, $2^{\text {nd }}$ Ed. Springfield: Charles C Thomas.122-5.
Stephenson T and Bialas Y (1996): Estimation of the age of bruising Archives of disease in Childhood. 74: 53-55.

Thavarajah D, Vanezis P and Perrett D (2012): Assessment of bruises age on dark-skinned individuals using tristimulus colorimetry. Med. Sci. Law. 52: 6-11.

Trujillo O, Vanezis P and Cermignanib M (1996): Photometric assessment of skin color and lightness using a tristimulus calorimeter: reliability of inter and intra-investigator observations in healthy adult volunteers. Forensic Sci. Inter. 81: 1-10.

Valle M and Zamoirini MP (2007): Skin and subcutaneous tissue In: Bianchi S, Martiloni $\mathrm{C}$, eds. Ultrasound of the musculoskeletal system. Chapter 1. Springer: Berlin.19-43.

Vanezis P (2001): Bruising: Concepts of Aging and Interpretation. Essentials of autopsy practice. PP 221-240.

Yajima Y, Nata M and Funayma M (2003): Spectrophotometric and tristimulus analysis of the colors of subcutaneous bleeding in living persons. Leg Med. 5: 342-3.

\section{الملخص العربي}

\section{إمكانية تحديد عمر الكدمات في الأطفال الأحياء بإستخدام الموجات فوق الصوتية عالية التردد بالإضافة إلى بلى بالي

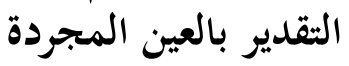

\footnotetext{
سحر محمد مصطفي'

تعتبر الكدمات إصابة هامة في نظر القانون و من تخم أصبح تحديد عمر الكدمات من الإجراءات الهامة في الإعدادات الروتينية

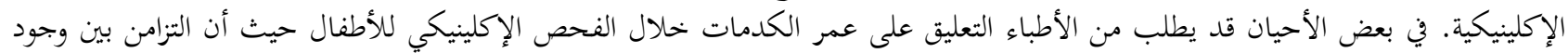

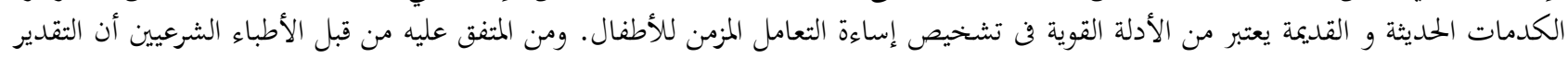

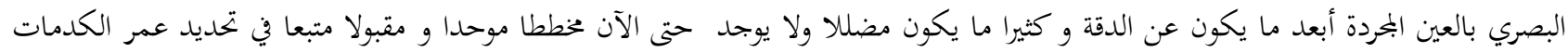

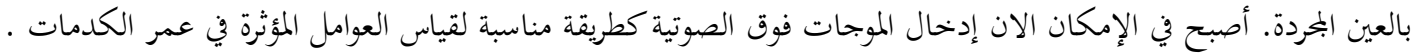

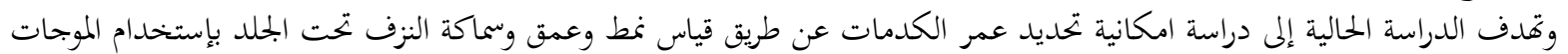

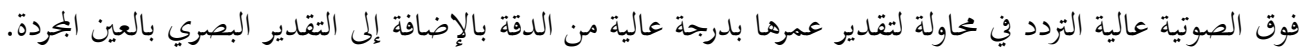

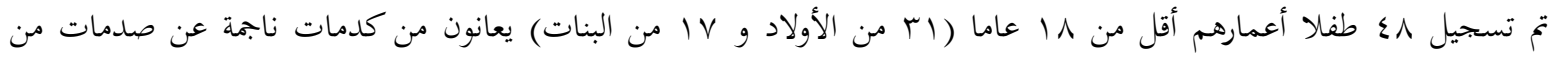
الحوادث وتم تسجيل التاريخ المرضى و الفحص الإكلينيكي للأطفال.

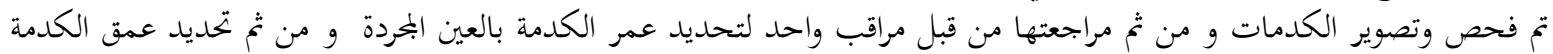

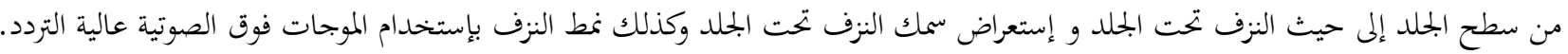

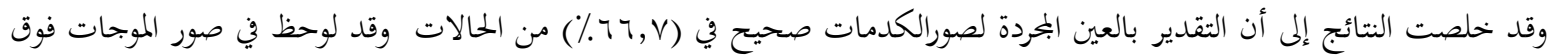

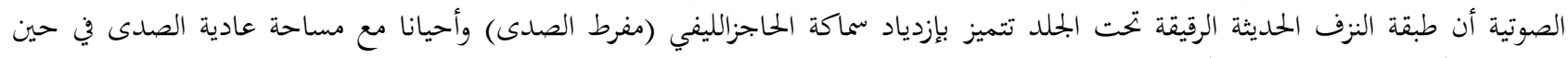
لوحظ في الكدمات الحديثة السميكة منطقة مفرطة الصدى منتشرة حول الحاجز الحفيثة الليفي.

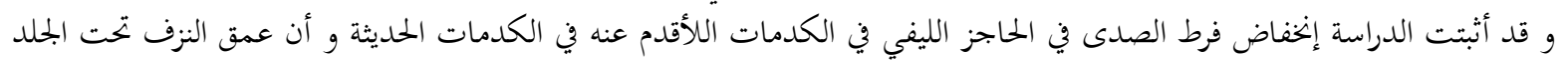

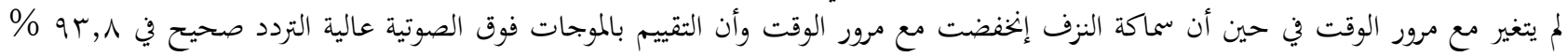
من الحالات. وخلصت النتائج إلى أن الموجات فوق الصوتية عالية التردد يمكن أن توفر تقييما دقيقا لنمط وعمق وسمك الكدمات وتسمح بتقديرات

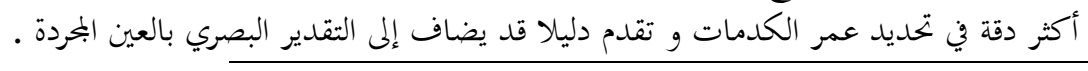
ا قسم الطب الثرعي والسموم الإكلينيكية - كلية الطب - جامعة قناة السويس
} 